\title{
Patrick Coleman, Anger, Gratitude, and the Enlightenment Writer
}

\section{Marisa Ferrarini}

\section{Q OpenEdition}

1 Journals

\section{Edizione digitale}

URL: https://journals.openedition.org/studifrancesi/4681

DOI: $10.4000 /$ studifrancesi.4681

ISSN: 2421-5856

\section{Editore}

Rosenberg \& Sellier

\section{Edizione cartacea}

Data di pubblicazione: 1 avril 2012

Paginazione: 146-147

ISSN: 0039-2944

\section{Notizia bibliografica digitale}

Marisa Ferrarini, «Patrick Coleman, Anger, Gratitude, and the Enlightenment Writer», Studi Francesi

[Online], 166 (I | LVI) | 2012, online dal 30 novembre 2015, consultato il 19 novembre 2021. URL: http:// journals.openedition.org/studifrancesi/4681 ; DOI: https://doi.org/10.4000/studifrancesi.4681

Questo documento è stato generato automaticamente il 19 novembre 2021.

\section{(c) (i) (9)}

Studi Francesi è distribuita con Licenza Creative Commons Attribuzione - Non commerciale - Non opere derivate 4.0 Internazionale. 


\title{
Patrick Coleman, Anger, Gratitude, and the Enlightenment Writer
}

\author{
Marisa Ferrarini
}

\section{NOTIZIA}

PATRICK COLEMAN, Anger, Gratitude, and the Enlightenment Writer, New York, Oxford

University Press, 2011, pp. 250.

1 Il libro si propone di offrire una nuova prospettiva sull'idea di sociabilità nel Settecento, esaminando come gli scrittori francesi s'interroghino sulla convenienza della rabbia e della gratitudine nella vita sociale.

2 Quando la rabbia è condannata come mancanza di autocontrollo e quando è lodata come rivendicazione della dignità umana? Chi è autorizzato ad arrabbiarsi e contro chi? Bisogna essere riconoscenti ed è giusto che la riconoscenza sia un dovere? Rispondere a simili domande significa, per l'autore, fornire una via di accesso alla comprensione di una tensione fondamentale nella cultura moderna: come l'aspirazione all'indipendenza personale possa essere riconciliata o no con il riconoscimento che la benevolenza o l'ostilità degli altri, anzi del mondo stesso, ha un ruolo essenziale nella costruzione del sé.

3 I giudizi contraddittori sull'adeguatezza di rabbia e gratitudine rivelano anche una sostanziale ambivalenza nel pensiero illuministico circa il tipo di norme che dovrebbero regolare l'interazione umana. La vita sociale dovrebbe essere basata soltanto su diritti e doveri legali, applicabili personalmente a tutto? O dovrebbe essere regolata da informali e più flessibili regole di riconoscenza personale, supportate dalla pressione dell'opinione più che dal potere della legge? Eliminando le occasioni di affronto o favore personale, il primo di questi schemi fornirebbe gradito sollievo dagli oneri di rabbia e gratitudine. Stando al secondo, la prontezza nel commettere e ricevere offesa, accettare e restituire un favore, è considerata un tratto cruciale della dignità 
umana, di ciò che uno deve a se stesso e agli altri, e dovrebbe essere coltivata più che limitata.

4 Il libro è incentrato sulla rappresentazione delle transazioni emozionali che implicano rabbia e gratitudine nelle opere di quattro grandi autori del Settecento. Challe, Marivaux, Rousseau e Diderot utilizzano la retorica dell'emozione per elogiare o criticare, per spingere i propri lettori a protestare contro ciò che giudicano sbagliato o manifestare apprezzamento per ciò che ritengono giusto. Questi scrittori non sono ministri di una chiesa o di uno stato e pertanto hanno percorso una rotta difficile tra la pericolosità delle autorità politiche e le attese incostanti dei lettori. Hanno comunque trovato nel linguaggio della rabbia e della gratitudine una risorsa per affermare in modo plausibile la dignità della loro vocazione e il valore della loro opera.

5 Particolarmente interessante, in tal senso, perché riassume un po' tutto il pensiero dell'autore, è il capitolo 6 dedicato a Diderot («Resentment and Reflection in Le Neveu de Rameau», pp.190-225), che esamina il rapporto tra la giusta rabbia e il risentimento invidioso. La questione affrontata è se la dignità e l'indipendenza personale di qualcuno possa essere affermata in modo credibile, o se non ci sia scampo da un'umiliante dipendenza. La risposta di Diderot è illuminante: come il genio artistico, il filosofo trascende la rabbia e la gratitudine attraverso la percezione estetica. 